\title{
HEAD INJURY IN NEPAL: AN INSTITUTIONAL BASED PROSPECTIVE STUDY ON CLINICAL PROFILE, MANAGEMENT AND EARLY OUTCOME OF TRAUMATIC BRAIN INJURY IN EASTERN PART OF NEPAL
}

\author{
Kafle $P^{1 *}$, Khanal $B^{2}$, Yadav $D K^{3}$, Poudel $D^{4}$, Karki $T^{5}$, Cherian $I^{6}$
}

\section{Affiliation}

1. Lecturer, Department of Neurosurgery, Nobel Medical College and Teaching Hospital, Biratnagar, Nepal.

2. Lecturer, Department of Pediatric Medicine, Nobel Medical College and Teaching Hospital, Biratnagar, Nepal

3. Resident Doctor, Department of Neurosurgery, Nobel Medical College and Teaching Hospital, Biratnagar, Nepal

4. Lecturer, Department of Anaesthesiology, Nobel Medical College and Teaching Hospital, Biratnagar, Nepal

5. Lecturer, Department of Radiology, Nobel Medical College and Teaching Hospital, Biratnagar, Nepal

6. Associate Professor, Department of Neurosurgery, Nobel Medical College and Teaching Hospital, Biratnagar, Nepal

\section{ARTICLE INFO}

Received : 16 May, 2019

Accepted : 14 August, 2019

Published : 31 August, 2019

C) Authors retain copyright and grant the journal right of first publication with the work simultaneously licensed under Creative Commons Attribution License CC - BY 4.0 that allows others to share the work with an acknowledgment of the work's authorship and initial publication in this journal.

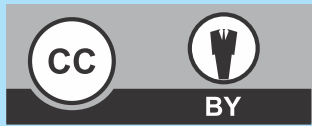

ORA 126

DOI: http://dx.doi.org/10.3126/bjhs.v4i2.25459

* Corresponding Author

Dr. Prakash Kafle

Lecturer

Department of Neurosurgery

Nobel Medical College and Teaching Hospital, Biratnagar, Nepal Email ID: prakashakflee@gmail.com

ORCID ID : https://orcid.org/0000-0001-5298-1128

\section{Citation}

Kafle P, Khanal B, Yadav DK, Poudel D, Karki T, Cherian I. Head Injury in Nepal: An Institutional Based Prospective Study on Clinical Profile, Management and Early Outcome of Traumatic Brain Injury in Eastern Part of Nepal BJHS 2019;4(2)9: 750 - 754

\section{ABSTRACT}

\section{Introduction}

Traumatic brain injuries (TBI) are among the worst consequences and are the major causes of death and disability worldwide. It is considered as silent epidemics affecting individuals of all the ages and one of the major burden of neorological disease. Hence, TBls are often overlooked and are sometimes called "the neglected disease of modern society". Presenting GCS is the best predictor of outcome.

\section{Objective}

The present study aims to portray the epidemiology, clinical profile, its management, early outcome and to evaluate the outcome predictors in a tertiary care center in eastern part of Nepal.

\section{Methodology}

This is a prospective cross-sectional study conducted at the Department of Neurosurgery, Nobel Medical College Teaching Hospital, Biratnagar, Nepal over the period of 1 year (October, 2016 - December 2017). The primary objective of this study was to review the etiology, clinical profile and early outcome of patients with TBI.

\section{Results}

During the study period, 1056 patients with head injuries were studied. Of these 202 cases required surgical intervention and 32 were excluded. Mean age of the study population was 38.7 years with the male to female ratio of 3.49:1. Road traffic accident was the most common cause of TBI (76\%). Overall mortality rate was $11.17 \%$. Unfavorable GOS at discharge was $43.5 \%$ and $26.1 \%$ at three months follow-up.

\section{Conclusion}

TBI continues to be a significant burden of neurosurgical care in major neurosurgical centers in Nepal. This study contributes data on the etiology and clinical profile of patients with TBI from tertiary care center of Nepal.

\section{KEYWORDS}

Road traffic accidents, traumatic brain injury, glasgow coma scale, glasgow outcome scale, mortality 


\section{INTRODUCTION}

Traumatic brain injury (TBI) is one of the most devastating types of injury. It affects all ages; however, majority of road traffic injuries (RTI) occurs in young adults of productive age group. It is one of the leading causes of death and disability worldwide. ${ }^{1} \mathrm{TBI}$ is heterogeneous in terms of pathophysiology, clinical presentation, and outcome, with case fatality rates ranging between $<1 \%$ in mild TBI up to $40 \%$ in severe TBI. $^{1}$ Due to rapid surge in urbanization, motorization and economical liberation, many Asian countries have an increased risk for TBI. ${ }^{2}$ In Asian countries, health systems that are often not able to provide adequate treatment and rehabilitation services to TBI patients, creates a 'double risk'. There is a gap in literature on health information system on epidemiological data especially in Asian population. The economic consequences of TBI are reported to be enormous, and yet estimates of the cost of TBI within Asia could not be found in the literature. It is important to elucidate the true burden of disease in Asia in order to tailor specific prevention programs aimed at alleviating this increasing epidemic as TBI has the preventable nature.

Primary brain injury occurs at the moment of impact leading to only a part of brain to be damaged. Numerous secondary brain insults (SBIS), both intracranial (hematoma, vasospasm, edema, and hydrocephalus) and extracranial or systemic SBI, complicate the initial damage in the ensuing hours and days and lead to secondary brain injury. The primary clinical objective after severe TBI is to prevent secondary brain injury, a common sequalae to the primary mechanical impact. In the ICU, the mainstay of treatment of patients with $T B I$ is the prevention of systemic $S B I$ such as hypoxemia, hypotension, ischemia, hypercapnia, hypocapnia, hyperthermia, acute anemia, hypertension, hyperglycemia, hypoglycemia, and hyponatremia. Most commonly, TBI patient presents with headache and vomiting followed by skull fracture with history of loss of consciousness (LOC). Nasal bleed, ear bleed, ecchymosis over mastoid (battle's sign) and CSF rhinorrhea/otorrhoea are clinical findings suggestive of basal skull fractures. Neurological assessment for assessing severity of TBI is commonly done by Glasgow coma scale (GCS) but low score of GCS do not necessarily predict bad outcome. ${ }^{3}$ Traditionally, TBI has been classified by mechanism (closed vs penetrating), by clinical severity (Glasgow coma scale [GCS]), and by assessment of structural damage. ${ }^{4}$ The GCS has evolved into a universal classification system for the severity of TBI, and consists of the sum score (range 3-15) of the three components (eye, motor, and verbal scales). For assessment of severity in individual patients, the three components should be reported separately. There are numerous factors that determines the outcome in head injury patients namely age, sex, severity of injury, intracranial pathology, intracranial pressure and associated injuries. ${ }^{5}$ People with TBI-related disabilities have been associated with shorter lifespans. ${ }^{6}$ Ventura et al found that the lifespan of people with TBI related disabilities was reduced by approximately 8 years. ${ }^{7}$
The risk of death after a TBI has been estimated as 7 times greater than that of the general population in the first year after injury and 5.3 times greater than that of the population over an average of 7 years after injury. ${ }^{8,9}$ Conditions that promote a shorter lifespan among those persons with a TBI were seizures, sepsis, digestive conditions, pneumonia, and other respiratory conditions, as well as external causes and unintentional injury. ${ }^{10} \mathrm{TBI}$ is also associated with significant socioeconomic burden not only in Nepal but also in other developing countries. ${ }^{11} \mathrm{~A}$ worldwide interest in TBI is currently trending as it has been shown that its consequences are not only limited to the acute post injury phase, but chronic sequelae and severe long-term adverse outcomes, such as cognitive impairment and early onset dementia may develop. World Health Organization (WHO) predicts that TBI will be one of the most dominant causes of death and disability by the year of $2020 .{ }^{12}$ Despite the enormous progress in the understanding of TBI and the establishment of evidence-based guidelines for its management, studies have demonstrated considerable variations in the care of patients with severe TBI. ${ }^{13}$ Traumatic brain injuries are the neglected disease of modern society and are commonly overlooked even by neurosurgeons and it derives only little attention from the policy makers both from national and international level. ${ }^{14}$ Nobel Medical College Teaching hospital is one of the largest tertiary care centers situated in the eastern part of Nepal with round the clock neurosurgical facilities with neurosurgery dedicated 34 ICU beds. Hence the present study seems feasible at this centre. Developing countries are facing major challenges of prevention, prehospital care, and rehabilitation in their rapidly changing environments to reduce the burden of TBIs. This study aims to describe the epidemiological, clinical characteristics, and short-term outcomes of patients with TBI admitted to our institute during the study period.

\section{METHODOLOGY}

This is a prospective cross-sectional study conducted in the Department of Neurosurgery at Nobel Medical College Teaching hospital, Biratnagar Nepal from October 2016 to December 2017. All patients aged 16 years and older with the diagnosis of TBI were included in the study. Post cardiopulmonary resuscitation (CPR) cases, patients with significant other system injuries, which could affect the GCS and patient transferred in from other hospitals during treatment or those who declined active treatment, were excluded from the study.

Glasgow Coma scale was assessed after resuscitation and they were classified based on severity of head injury defined as severe (GCS 3-8), moderate (GCS 9-12) and mild (GCS 1315).Patients were managed with the standard head injury protocol and then discharged once they met the discharge criteria. The Outcome of patients was assessed at the time of discharge and at 3 months follow-up using Glasgow outcome scale (GOS). Outcome was assessed using the 5 point Glasgow Outcome Score (GOS) at discharge and 3 months. GOS was dichotomized in unfavorable (GOS 1-3) 
versus favorable (GOS 4-5). Analysis of frequency, mean, ratio and range of the collected data were done using Microsoft Excel 2007 and SPSS version 20. Spearman's correlation coefficient was used to see the significant correlation between GCS and GOS. For the test of statistical significance $\mathrm{P}$ value of $<0.001(99.9 \% \mathrm{Cl})$ was considered as significant.

\section{RESULT}

Over the study period 1056 cases were admitted with diagnosis of head injury. Two hundred and two cases underwent surgical management. Thirty-two patients were excluded for various reasons as already mentioned in exclusion criteria. The remaining 170 patients were the subject of this study and. There were 129 cases of severe head injury. Remaining 854 cases were managed conservatively.

\begin{tabular}{|c|c|c|c|c|}
\hline & \multicolumn{4}{|c|}{ Types Head injury } \\
\hline & Mild & Moderate & Severe & Total \\
\hline Admitted cases & 675 & 235 & 146 & 1056 \\
\hline Operated cases & 42 & 31 & 129 & 202 \\
\hline
\end{tabular}

\section{Age distribution}

In the present study the age of study population ranged from $16-82$ years with the mean of 38.7 years as shown in the table 2 .

\begin{tabular}{ccc}
\hline $\begin{array}{c}\text { Table 2: Age distribution of the study population } \\
\begin{array}{c}\text { Age } \\
\text { group(year) }\end{array}\end{array}$ & $\begin{array}{c}\text { Frequency(n) } \\
\text { Percentage (\%) }\end{array}$ \\
\hline $\mathbf{2 0}$ & 207 & 19.6 \\
$\mathbf{2 1 - 4 0}$ & 406 & 38.5 \\
$\mathbf{4 1 - 6 0}$ & 250 & 23.7 \\
$\mathbf{6 1 - 7 0}$ & 179 & 16.9 \\
$>\mathbf{8 0}$ & 14 & 1.3 \\
Total & $\mathbf{n}=\mathbf{1 0 5 6}$ & $\mathbf{1 0 0 \%}$ \\
\end{tabular}

\section{Sex distribution}

Among total admission, 821 were males and 235 were females with male to female ratio of 3.49:1 (Figure 1).

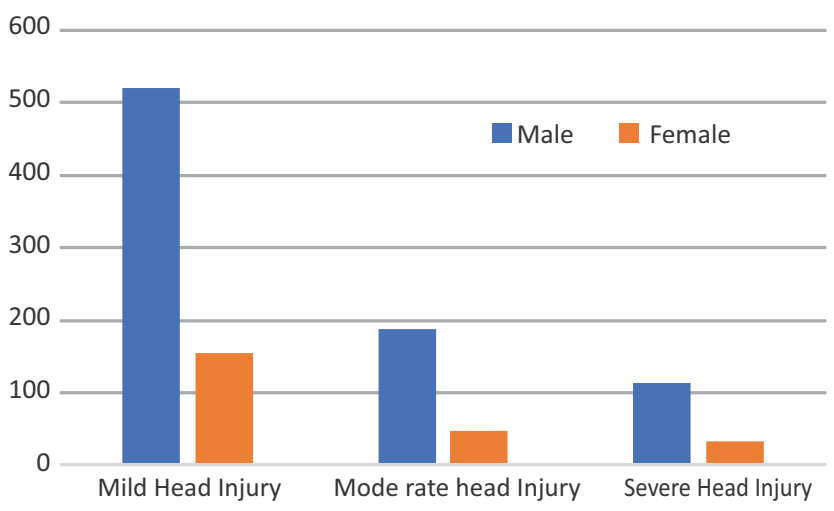

Figure 1: Sex distribution

\section{Mode of Injury}

In the present study, road traffic accident was the most common mode of head injury followed by fall injury as shown in figure 2 .

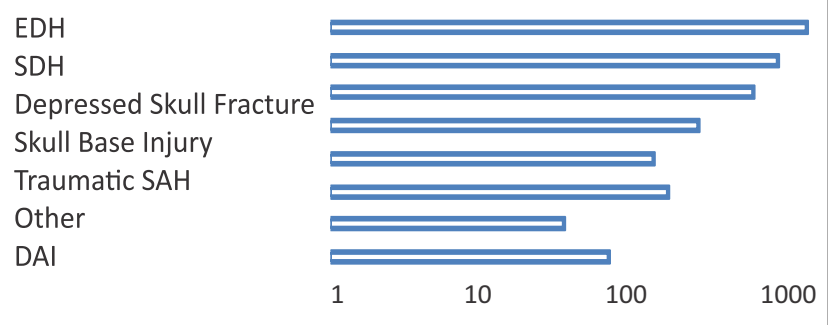

Figure 2: Mode of injury

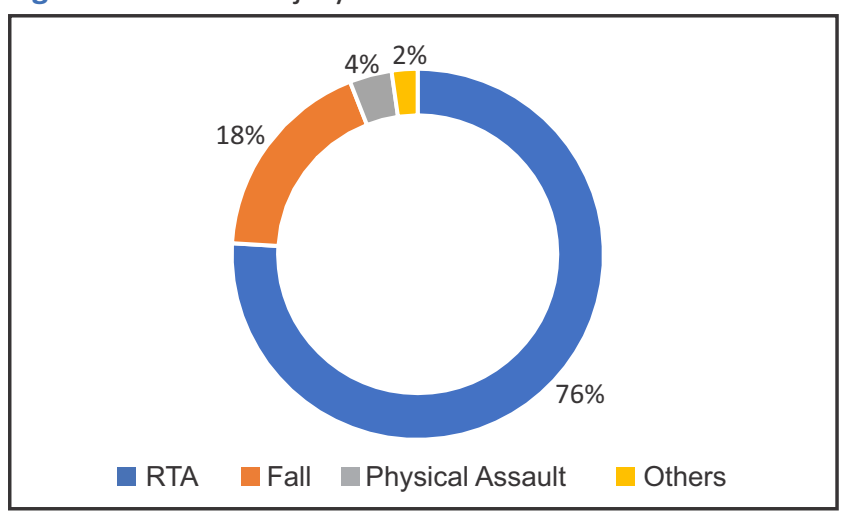

GOS: Glasgow Outcome Scale, ${ }^{*}=$ statistically significant association

\begin{tabular}{|c|c|c|c|c|c|c|}
\hline \multicolumn{7}{|c|}{ Head injury } \\
\hline & & Mild & Moderate & Severe & Total & Remarks \\
\hline \multirow{3}{*}{$\begin{array}{c}\text { GOS at } \\
3 \text { months } \\
\text { follow-up }\end{array}$} & Favorable & 28 & $25^{*}$ & $60^{*}$ & 113 & \multirow{3}{*}{$\begin{array}{l}\text { Mortality at } 3 \text { months } \\
\text { follow-up }(n=2)\end{array}$} \\
\hline & Unfavorable & 0 & 1 & 37 & 38 & \\
\hline & Total & $28 *$ & 26 & 97 & 151 & \\
\hline
\end{tabular}

\section{DISCUSSION}

Traumatic brain injuries (TBI) are among the worst consequences and are the major causes of death in patients under the age of 25 years. It is also the leading cause of trauma related coma and disabilities. In developed countries the rate of deaths induced by head injury has been about $21 \%$ in the first month and this rate goes up to $50 \%$ in developing countries. ${ }^{15}$ The importance of the problem of TBI is always underestimated due to the lack of research and good quality data in Nepal. This study was conducted to minimize the literature gap. Several clinical characteristics of severe traumatic brain injury influence patients' outcome. The most important characteristics are the patient's age, the initial Glasgow coma score, the presence or absence of pupillary abnormalities, and to a lesser extent, CT-based classification of the severity of the injury. ${ }^{16}$ In the present study, TBI predominated in young men in the form of severe TBI and mostly occurred due to RTAs. Patients with severe TBI have long hospital stay demanding high-level care and extra resources in a resource constrained place like Nepal. In the present study, patients' age ranged from $16-82$ years and 
mean age was 38.7 years. The male to female ratio was 3.49:1, which correlates with previously published studies. ${ }^{17-20}$ It is also observed that young male is most commonly affected by TBI. A statistical significant association was observed in low Glasgow coma score and mortality as an outcome as illustrated in table $3 \& 4$. These findings are consistent with other studies. ${ }^{11}$ The most common mode of injury in this study was road traffic accident followed by accidental fall injury which shows the same mode of injury as in other studies. ${ }^{21,22}$ Agrawal A et al conducted a retrospective study to evaluate and describe the epidemiological and clinical characteristics of patients with traumatic brain injury and their clinical outcomes following admission to a rural, tertiary care teaching hospital in India. In his study, road traffic crashes was the leading cause of TBI in rural Maharashtra affecting mainly young adult males and at least $10 \%$ of survivors had moderate or more severe TBI-related disabilities. He concluded that future research should include prospective, population based studies to better elucidate the incidence, prevalence, and economic impact of TBI in rural India. ${ }^{12}$ In the present study $19.13 \%$ underwent surgical treatment whereas $80.87 \%$ were managed conservatively. In a study by Myburgh et al, the operative cases comprised of 37-67\% of total TBI. ${ }^{23}$ The outcome of TBI depends on the GCS at the time of presentation. ${ }^{24,25}$ GOS at discharge and at 3 months follow-up was better for those with moderate head injury compared to severe head injury. Low Glasgow Coma Score at admission was significantly associated with mortality as an outcome. This report is similar to many other reports from different literature. ${ }^{26}$ In a study by G. Gururaj, recovery rate was higher among mild TBIs (65\%) compared with moderate and severe TBIs (55\% and $38 \%) .{ }^{26}$ In this study unfavorable GOS at discharge was $43.5 \%$ and $26.1 \%$ at three months follow-up. Overall mortality rate was $11.17 \%(n=19)$. Availability of early and appropriate care after an injury is a major determinant in avoiding secondary injuries and death. ${ }^{1}$ In a study done by $\mathrm{Wu} X$ et al in China to investigate the epidemiological data on TBI based on a prospective multicenter trial, a total of 14,948 of cases of TBI were identified from 77 hospitals in eastern China with 11,446 men (76.6\%) and 3,502 women (25.4\%). Unlike male adolescents and young adults were affected more often by brain injury in this study. Traffic accidents (60.9\%), knock on head (13.4\%), and falls (13.1\%) were the leading causes of patients with TBI which resembles our findings.The distribution of head injury severity, on the basis of Glasgow Coma Scale scores, was mild in $62 \%$, moderate in $18.1 \%$, and severe in $20 \%$ for all cases. In contrast our study showed $56.99 \%$ with mild head injuries followed by $21.14 \%$ moderate and $21.86 \%$ severe injuries. It is now high time to establish a standardized surveillance system of TBI incidence, risk factors, causes and outcomes for development of new, more effective, targeted strategies to prevent TBI in Nepal targeting the cause.

\section{CONCLUSION}

Traumatic brain injury continues to be a significant burden of neurosurgical care. Majority of head injuries were seen in male and middle age group due to more outdoor activities. Knowledge about the causes, pattern, and distributions about TBI patients from this study is expected to be helpful in policy making, research, health management, rehabilitation and development of standard protocols for research and management at the national level in Nepal and other developing nations as well. Appropriate data can help direct resources to developing health systems in the region, which can address the need for preventable, neurosurgical, and rehabilitation services for TBI.

\section{RECOMMENDATIONS}

Traumatic brain injury is characterized as the "silent epidemic". It contributes to a substantial number of deaths and cases of permanent disability. Programs and policies to reduce traumatic brain injury (TBI) rates are assumed to help in reducing injury rates overall thereby reducing the health burden.

\section{LIMITATION OF THE STUDY}

This study is a single center study. Those cases of head injury, which were not admitted primarily in our center due to unavailability of vacant ICU bed, may have contributed to a significant selection bias. Outcome assessment of only 3 months duration may not be sufficient to comment on the outcome.

\section{ACKNOWLEDGEMENTS}

Firstly, I thank Almighty GOD for all the grace he has bestowed upon me. This work is the culmination of the help, encouragement and guidance from a number of people. I would like to thank them all. I would like to acknowledge my deep sense of gratitude to my colleague, fellows and sisters. I acknowledge my gratitude to the patients for their co-operation without whom the study would have been incomplete.

\section{CONFLICT OF INTEREST}

None declared.

\section{FINANCIAL DISCLOSURE}

There is no additional financial burden to the patients. No pharmaceutical companies have supported the study. The author does the minimal required expenses. 


\section{REFERENCES}

1. Vicky C Chang. Epidemiology of work -related Traumatic Brain injury:A systematic Review.Am J Ind Med 2015;58:353-77.

2. Puvanachandra $P$, Hyder AA. The burden of traumatic brain injury in Asia: a call for research. Pak J Neurol Sci. 2009;4(1):27-32.

3. Waxman K, Sundine MJ, Young RF. Is early prediction of outcome in severe head injury possible? Archives of surgery. 1991;126(10): 1237-42.

4. Teasdale G, Jennett B. Assessment of coma and impaired consciousness. A practical scale. Lancet 1974; 2: 81-84.

5. Mushkudiani NA, Engel DC, Steyerberg EW, Butcher I, Lu J, Marmarou A et al. Prognostic value of demographic characteristics in traumatic brain injury: results from the IMPACT study. Journal of Neurotrauma. 2007;24(2):259-69.

6. Zaloshnja E, Miller T, Langlois JA, Selassie AW. Prevalence of longterm disability from traumatic brain injury in the civilian population of the United States, 2005. The Journal of head trauma rehabilitation. 2008;23(6):394-400.

7. Ventura T, Harrison-Felix C, CarlsonN. Postacute mortality following traumatic brain injury: a population based study. Arch Phys Med Rehabil 2009;91: 20-29.

8. Selassie AW, McCarthy ML, Ferguson PL, Tian J, Langlois JA. Risk of posthospitalization mortality among persons with traumatic brain injury, South Carolina 1999-2001. The Journal of head trauma rehabilitation. 2005;20(3):257-69.

9. Brown AW, Leibson CL, Malec JF, Perkins PK, DiehI NN, Larson DR. Long-term survival after traumatic brain injury: a population-based analysis. NeuroRehabilitation. 2004;19(1):37-43.

10. Harrison-Felix C, Whiteneck G, DeVivo MJ, Hammond FM, Jha A. Causes of death following 1 year postinjury among individuals with traumatic brain injury. The Journal of head trauma rehabilitation. 2006;21(1):22-33.

11. Hutchison JS, Ward RE, Lacroix J, Hébert PC, Barnes MA, Bohn DJ et al. Hypothermia therapy after traumatic brain injury in children. New England Journal of Medicine. 2008;358(23):2447-56.

12. Agrawal A, Galwankar S, Kapil V, Coronado V, Basavaraju SV, McGuire LC, et al. Epidemiology and clinical characteristics of traumatic brain injuries in a rural setting in Maharashtra,India 2007-2009.Int J CritIIInInjSci 2012;2:167-71.
13. Ghajar J, Hariri RJ, Narayan RK, lacono LA, Firlik K, Patterson RH. Survey of critical care management of comatose, head-injured patients in the United States. Critical care medicine. 1995;23(3):560-7.

14. Bajracharya A, Agrawal A, Yam B, Agrawal C, Lewis O. Spectrum of surgical trauma and associated head injuries at a university hospital in Eastern Nepal. J Neurosci Rural Pract 2010;1: 2-8.

15. Ingebrigtsen T, Romner B, Kock-Jensen C. Scandinavian guidelines for initial management of minimal, mild, and moderate head injuries. Journal of Trauma and Acute Care Surgery. 2000 Apr 1;48(4):760-6.

16. Choi SC, Narayan RK, Anderson RL, Ward JD. Enhanced specificity of prognosis in severe head injury. Journal of neurosurgery. 1988 Sep 1;69(3):381-5.

17. Fleminger $S$, Ponsford J. Long term outcome after traumatic brain injury.BMJ 2005;331:1419-20.

18. Anand $M$, NageshKR.pattern of fatal head injuries due to vehicular accidents in Manipal.J Indian Acad Forensic Med 2005;27:971-73.

19. Marmarou A, Lu J, Butcher I, McHugh GS, Murray GD, Steyerberg EW, et al. Prognostic value of the Glasgow Coma Scale and pupil reactivity in traumatic brain injury assessed pre-hospital and on enrollment: An IMPACT analysis. J Neurotrauma 2007;24:270-80.

20. Murthy TV, Bhatia P, Sandhu K, Prabhakar T, Gogna RL. Secondary brain injury: Prevention and intensive care management.Indian J Neurotrauma 2005;2:7-12.

21. Peeters W, van den Brande R, Polinder S, Brazinova A, Steyerberg EW, et al. Epidemiology of traumatic brain injury in Europe. Actaneurochirurgica. 2015 Oct 1;157(10):1683-96.

22. Abelson-Mitchell N. Epidemiology and prevention of head injuries: literature review. Journal of clinical nursing. 2008 Jan;17(1):46-57.

23. Myburgh JA, Cooper DJ, Finfer SR, Venkatesh B, Jones D, Higgins A, et al. Epidemiology and 12-month outcomes from traumatic brain injury in Australia and New Zealand. J Trauma 2008;64:854-62.

24. Tran TM, Fuller AT, Kiryabwire J, Mukasa J, Muhumuza M, Ssenyojo H et al. Distribution and characteristics of severe traumatic brain injury at Mulago National Referral Hospital in Uganda. World neurosurgery. 2015 Mar 1;83(3):269-77.

25. Ghajar J. Traumatic brain injury. The Lancet. 2000 Sep 9;356(9233): 923-9

26. Gururaj G. Epidemiology of traumatic brain injuries: Indian scenario. Neurological research. 2002 Jan 1;24(1):24-8. 